
[Primer premio de la III Olimpiada de Filosofía organizada por FICUM,
sección secundaria]

\title{
Ilia, y el camino de la felicidad
}

Ilia, the way to happiness

\author{
ANA TIMONET PÉREZ \\ Malaga Institute of Tecbnology (España)
}

recibido: 25.06 .2015

aceptado: 26.07 .2015

\section{RESUMEN}

Este trabajo es el ganador de la III Olimpiada de Filosofía que organiza FICUM en la modalidad de secundaria. Ana Timonet presentó su particular respuesta a la pregunta por el camino de la felicidad.

\section{PALABRAS CLAVE}

FELICIDAD, CAMINO, ESFUERZO, AMISTAD

\begin{abstract}
This work is the winner of the III Olympiad of Philosophy that FICUM organized in the section "secundary school I". Ana Timonet presented her special answer to the question about the way to happiness.
\end{abstract}

KEY WORDS

HAPINESS, WAY, EFFORT, FRIENDSHIP

Claridades. Revista de filosofía, 7 (2015), pp.151-154

ISSN: 1889-6855 ISSN-e: 1989-3787 Dl.: PM 1131-2009

Asociación para la promoción de la Filosofía y la Cultura (FICUM) 


\section{TENEMOS QUE SER VALIENTES}

Y PONERNOS EN EL CAMINO QUE NOS LLEVE A LA FELICIDAD

NARRADOR: UNA MAÑANA EN EL MUNDO DE FANTASÍA, Ilia notó algo extraño en el ambiente. De pronto, se dio cuenta de que las plantas y la vegetación se estaban muriendo por un veneno que había en el aire.

Ilia: Supongo que este veneno será obra del malvado mago Maltazar. Iré en su busca para impedirle seguir con su maléfico plan.

Narrador: Pero el camino hasta el palacio de Maltazar era peligroso. Ilia no lo sabía.

\section{CUIDADO CON LOS FALSOS REMEDIOS}

Narrador: Iba caminando cuando de repente Ilia se metió en el bosque de las ciénagas, cuyas aguas están encantadas. Si sientes tristeza en el corazón, te vas hundiendo muy lentamente en las aguas cenagosas. Cuando Ilia cruzó las aguas, se encontró en un campo de amapolas. Ilia: Vaya, iqué flores tan bonitas. Y a ellas no les afecta el veneno! Qué raro...

Narrador: Ilia no sabe que cuando hay muchas flores de éstas, su olor es $\tan$ fuerte que quien lo respira, se duerme. Si el durmiente no se aleja de las flores, sigue durmiendo eternamente.

Narrador: Se estaba quedando profundamente dormida, cuando la maga Agaza apareció para rescatarla y llevarla a su casa.

\section{NO ES UN CAMINO QUE PODAMOS HACER SOLOS}

Ilia: Gracias por salvarme.

Agaza: He conocido tu propósito, y vengo a ayudarte.

Ilia: ¡Gracias!

Agaza: Vámonos, nos esperan las puertas gemelas y la puerta del espejo.

\section{HAY QUE AFRONTAR LOS PROBLEMAS}

Narrador: Las puertas gemelas llevan a dos sitios diferentes. Una lleva a la gruta de las tinieblas. Otra lleva a la sala del espejo mágico, donde tendrán que enfrentarse a sus mayores miedos. Sólo si se consiguen cruzar se puede llegar al palacio de Maltazar.

Después de un largo camino, por fin llegaron a las puertas gemelas.

Claridades. Revista de filosofía 7 (2015) 
Ilia: ¿Éstas son las puertas gemelas?

Agaza: Sí. Entraré yo primero. Si no vuelvo enseguida, entra por la otra puerta.

Narrador: Pasados diez minutos...

Ilia: ¡Ya he esperado bastante! ¡Allá voy!

Narrador: Y una vez dentro...

Spirit: Hola viajante.

Ilia: (Aterrada) ¿Quién eres? ¿Dónde está Agaza?

Spirit: Esperándote fuera. Yo te guiaré hasta el espejo. Debes meterte sin titubear y andar siempre recto.

Ilia: ¿Vendrás conmigo hasta la guarida de Maltazar?

Spirit: ¡Claro!

\section{NO HACE FALTA NINGÚN PODER PARA SER ESPECIAL Y TENER ÉXITO AL TRANSITAR POR EL CAMINO DE LA FELICIDAD}

Narrador: Cruzaron el espejo y allí les esperaba Agaza. Delante de ellas había un largo camino, por el que las tres amigas comenzaron a caminar. Y mientras caminaban...

Spirit: Eres especial Ilia, seguro que lo conseguiremos.

Ilia: ¿Por qué dices eso? Yo no tengo ningún poder.

Spirit: Tienes el arco iris en los ojos.

Ilia: Mira, por fin tenemos ahí delante el Castillo de Maltazar.

Agaza: Yo no puedo continuar más. Me encuentro muy débil. Oh, ¡siento cómo Maltazar me está teletransportando a su guarida! ¡Socorro!

\section{NO HAY MAYOR PODER QUE LOS AMIGOS}

Narrador: Las tres amigas fueron teletransportadas al castillo. Donde aparecieron atadas de manos y pies.

Maltazar: Lo siento, pero llevo mucho tiempo queriendo hacer esto. Ahora meteré a Agaza en su encerramiento para siempre. Primero, con el carrillón de los sueños de oro dormirá eternamente. Segundo: sueños de esencia de oscuridad para que su celda siempre esté oscura. Tercero: ataúd de cristal del que nunca podrá salir. Cuarto: Un poco de pelo verde de las tres brujas del camino oscuro para sellar la cerradura. Quinto: una máscara de piedra para tapar su belleza. Sexto: la cadena de oro para atarla y mantenerla cautiva. Séptimo y último: Concentrado de tristeza que esparciré por encima para que nadie nunca la recuerde.

Claridades. Revista de filosofía 7 (2015) 
Ilia: jamás harás daño a mis amigas.

Maltazar: creo que ya lo he hecho.

\section{LUCHAR EN NOMBRE DE LA FELICIDAD}

Ilia: Todavía no. ¡Spirit date prisa!

Narrador: Spirit hace un hechizo para deshacer el concentrado de tristeza. Y lanza un segundo hechizo gritando "en nombre de la felicidad te ordeno que nos desates!". Las tres quedaron desatadas. Pensando en algo bonito consiguieron abrir el ataúd de cristal. Con agua consiguieron abrir la máscara de piedra, con cariño desataron el nudo de los pelos de bruja, con polvo de estrellas eliminaron el maleficio de la oscuridad. Y rompiendo el carrillón de los sueños, con mucha pasión, consiguieron despertar a Agaza.

Narrador: Maltazar entendió que estando las tres unidas no tenía ninguna posibilidad y se marchó gritando que volvería pronto.

Agaza: Me habéis salvado...

Spirit: Claro, eres nuestra amiga.

Ilia: Jamás te abandonaríamos.

AnA Timonet PÉREz es alumna de primero de ESO en el MIT School (Málaga, España). Este trabajo que aquí publicamos es el ganador de la III Olimpiada de Filosofía organizada por FICUM, en la sección de secundaria.

Lineas de investigación:

Publicaciones recientes:

Dirección electrónica: mrrojas@teacher.mitschool.com

Claridades. Revista de filosofía 7 (2015) 